\title{
Helicobacter pylori infection in asymptomatic rural Bangladeshi population
}

\author{
Mir Masudur Rhaman ${ }^{1}$, Fahmida Rahman², Sraboni Mazumder², \\ M. Abu Sayeed ${ }^{1}$, Jalaluddin Ashraful Haq ${ }^{2 *}$ \\ ${ }^{1}$ Department of Community Medicine, Ibrahim Medical College, Dhaka, Bangladesh; \\ ${ }^{2}$ Department of Microbiology, Ibrahim Medical College, Dhaka, Bangladesh
}

\begin{abstract}
Background and objectives: The prevalence of Helicobacter pylori infection differs in urban and rural population. In our country, no previous study investigated the $H$. pylori infection in rural population. The aim of the present study was to find out the status of $H$. pylori infection among the Bangladeshi asymptomatic rural adult population.
\end{abstract}

Material and Methods: This cross-sectional study was carried out in a rural area located about $40 \mathrm{~km}$ north-east of capital Dhaka. Apparently healthy non-diabetic, pre-diabetic and diabetic adults (18 years and above) were enrolled in this study. A structured questionnaire was developed to record the socio-demographic and clinical information. $H$. pylori infection status was determined by the presence of anti- H. pylori IgG antibody in blood. Serum anti-H.pylori IgG antibodies were determined by immunochromatographic test (ICT) method.

Results: A total number of 180 apparently healthy adult individuals were enrolled of which 112, 40 and 28 were non-diabetic, pre-diabetic and diabetic respectively. Out of 180 individuals, anti- $H$. pylori IgG was present in 70 (38.9\%, $\mathrm{Cl}$ : $32.1,46.2)$ cases. Infection rate was $50 \%, 27.5 \%$ and $43.5 \%$ in $19-30,31-50$ and $>50$ years age group respectively. Infection rate was significantly $(p<0.05)$ low in $31-50$ years age group compared to $19-30$ and $>50$ years age groups. H. pylori infection rates in male and female were $42.6 \%(\mathrm{Cl}: 29.2,56.8)$ and $37.3 \%(\mathrm{Cl}: 28.9,46.4)$ respectively $(p=0.50)$. There was no significant $(p>0.05)$ association of $H$. pylori infection with economic status, education level, occupation and tobacco consumption of the study population. The rate of $H$. pylori infection in non-diabetic, pre-diabetic and diabetic individuals were not significantly different from each other.

Conclusion: The study revealed a low prevalence of $H$. pylori infection in rural population of Bangladesh. There was no significant association of $H$. pylori infection with several sociodemographic status and diabetes.

IMC J Med Sci 2021; 15(1): 007

\section{Introduction}

H. pylori, a gastroduodenal pathogen, causes chronic gastritis and peptic ulcer disease and is associated with gastric cancer [1]. The prevalence of $H$. pylori infection is more in developing countries. Poverty-related factors including overcrowding, poor sanitation, unclean water and low education level are the main risk factors of acquiring $H$. Pylori [2]. The infection tends to become chronic unless it is treated with antimicrobials [3].

In developed countries, the prevalence ranges from $11-32 \%$ in adults $[4,5]$ and $10-16.7 \%$ in children $[6,7]$. On the hand, in developing countries, it

*Correspondence: Jalaluddin Ashraful Haq, Department of Microbiology, Ibrahim Medical College, 1/A Ibrahim Sarani, Segunbagicha, Dhaka 1000, Bangladesh.Email: jahaq54@yahoo.com 
ranges from $49-87 \%$ in adults $[8,9]$ and $9-78.6 \%$ in schoolchildren $[10,11]$. However, in some developing countries, the prevalence is decreasing. For example, in South Korea, a significant decrease in prevalence was observed from 1998 (66.9\%) to 2005 (59.6\%) [12]. Bangladesh is one of the developing countries having peptic ulcer disease as a common health problem. The seroprevalence was reported 92\% in 1997 [13] and $71.1 \%$ in 2008 [14] among the asymptomatic adults. In children, the prevalence was reported as $58 \%$ (0-4 years) to $82 \%$ (8-9 years) in Bangladesh $[15,16]$. The prevalence differs in urban and rural settings. In Vietnam, significantly higher prevalence of $H$. pylori infection was observed in urban area than in rural area. In the rural population of Vietnam, the risk for acquiring infection was $40 \%$ less than in the urban people [17].

In our country, no previous study investigated the $H$. pylori infection in asymptomatic rural population. Therefore, the primary aim of the present study was to find out the current prevalence status of $H$. pylori infection among the Bangladeshi asymptomatic adult rural population.

\section{Materials and Methods}

Study place and population: This cross-sectional study was carried out in a rural area named Sreepur under Gazipur district. The rural area is located about $40 \mathrm{~km}$ north-east of capital Dhaka. Apparently healthy non-diabetic, pre-diabetic and diabetic adults (18 years and above) were enrolled in this study. Diabetes mellitus (DM) and pre- diabetes were defined according to the criteria of American Diabetes Association [18]. Informed written consent was obtained from all the participants after explaining the nature and purpose of the study. A structured questionnaire (close ended) was developed and used to record the socio-demographic information and clinical history. It was pretested and checked for applicability before it was finally launched at the field to interview for data collection from the respondents.

Collection of blood and estimation of anti- H.pylori IgG antibody: $H$. pylori infection status was determined by the presence of anti- $H$. pylori IgG antibody in blood. Blood samples $(2.5 \mathrm{~mL})$ were collected aseptically from each participant by peripheral venipuncture under aseptic conditions. After collection, the serum was separated, aliquoted, refrigerated at $4^{\circ} \mathrm{C}$ and then transported to the microbiology laboratory in a cold box. Serum anti- $H$. pylori IgG antibodies were determined by ICT (immunochromatographic test) method using AimStep $^{\mathrm{TM}}$ H. Pylori Rapid Cassette test device (Germaine ${ }^{\circledR}$ Laboratories, Inc, USA). The test was performed and interpreted according to the manufacturer's instruction.

\section{Result}

A total number of 180 apparently healthy adult individuals were enrolled of which 112, 40 and 28 were non-diabetic, pre-diabetic and diabetic respectively. Out of 180 individuals, IgG antibody for $H$. pylori was present in 70 (38.9\%; $\mathrm{Cl}$ : 32.1,

Table-1: H. pylori infection according to age and gender of the study population

\begin{tabular}{|c|c|c|c|c|}
\hline Category & $\begin{array}{c}\text { Total } \\
\text { number }\end{array}$ & $\begin{array}{c}\text { Anti- H. pylori IgG positive } \\
\text { Number (\%) }\end{array}$ & $95 \% \mathrm{Cl}$ & p value \\
\hline All & 180 & $70(38.9)$ & $32.1,46.2$ & - \\
\hline \multicolumn{5}{|c|}{ Age (years) } \\
\hline $19-30^{\mathrm{a}}$ & 42 & $21(50)$ & $34.2,65.8$ & $0.017^{*}$ \\
\hline $31-50^{b}$ & 69 & $19(27.5)$ & $17.5,39.6$ & $0.05^{* *}$ \\
\hline$>50^{c}$ & 69 & $30(43.5)$ & $31.6,55.2$ & $0.504^{* * *}$ \\
\hline \multicolumn{5}{|l|}{ Sex } \\
\hline Male $^{\mathrm{a}}$ & 54 & $23(42.6)$ & $29.2,56.8$ & $0.505^{*}$ \\
\hline Female $^{b}$ & 126 & $47(37.3)$ & $28.9,46.4$ & \\
\hline
\end{tabular}


IMC J Med Sci 2021; 15(1): 007

Table-2: H. pylori infection according to socio-demographic characteristics of the study population

\begin{tabular}{|c|c|c|c|c|}
\hline Category & Total number & $\begin{array}{c}\text { Anti- H. pylori IgG positive } \\
\text { Number (\%) }\end{array}$ & $95 \% \mathrm{Cl}$ & p value \\
\hline \multicolumn{5}{|l|}{ Economic status } \\
\hline Middle class $^{a}$ & 90 & $39(43.3)$ & $32.9,54.2$ & $0.221^{*}$ \\
\hline Poor ${ }^{b}$ & 90 & $31(34.4)$ & $24.7,45.2$ & \\
\hline \multicolumn{5}{|l|}{ Education } \\
\hline Illiterate $^{a}$ & 91 & $32(35.2)$ & $25.4,45.9$ & $0.3^{*}$ \\
\hline $\mathrm{SSC} / \mathrm{HSC} /$ more $^{\mathrm{b}}$ & 89 & $38(42.7)$ & $32.3,53.6$ & \\
\hline \multicolumn{5}{|l|}{ Occupation } \\
\hline Farmer $^{a}$ & 34 & $16(47.1)$ & $29.8,64.9$ & $0.139 *$ \\
\hline Housewife $^{b}$ & 106 & $35(33)$ & $24.2,42.9$ & $0.106 * *$ \\
\hline Skilled worker ${ }^{c}$ & 40 & $19(47.5)$ & $31.5,63.9$ & $0.97 * * *$ \\
\hline \multicolumn{5}{|l|}{$\begin{array}{l}\text { Smoking/ Use of } \\
\text { tobacco leaf }\end{array}$} \\
\hline Yes $^{a}$ & 119 & 47 (39.5\%) & $30.7,48.9$ & $0.816^{*}$ \\
\hline $\mathrm{No}^{\mathrm{b}}$ & 61 & $23(37.70)$ & $25.6,51$ & \\
\hline
\end{tabular}

Table-3: H. pylori infection according to diabetes status

\begin{tabular}{lcccc}
\hline Category & Total number & $\begin{array}{c}\text { Anti- } \boldsymbol{H} \text {. pylori IgG positive } \\
\text { Number (\%) }\end{array}$ & $\mathbf{9 5 \%} \mathbf{C l}$ & p value \\
\hline Non-diabetic (Gr1) & 112 & $44(39.3 \%)$ & $30.2,48.2$ & $0.722^{*}$ \\
Pre-diabetic (Gr2) & 40 & $17(42.5 \%)$ & $27,59.1$ & $0.387^{* *}$ \\
Diabetic (Gr3) & 28 & $9(32.1 \%)$ & $15.9,52.4$ & $0.486^{* * *}$ \\
Pre-diabetic+ & 68 & $26(38.23)$ & $27.6,50.1$ & $0.889 * * * *$ \\
Diabetic (Gr4) & & & \\
\hline Note: Cl: confidence interval; $p$ value determined by chi square test; *Gr1 vs 2; **Gr2 vs 3; ***Gr1 vs 3; \\
$* * * *$ Gr1 vs Gr4.
\end{tabular}

46.2) cases.Table-1 shows the $H$. pylori infection status by age and gender. Infection rate was $50 \%$, $27.5 \%$ and $43.5 \%$ in $19-30,31-50$ and $>50$ years age group respectively. Infection rate was significantly $(p<0.05)$ low in $31-50$ years age group compared to $19-30$ and $>50$ years age groups. There was no significant $(p=0.5)$ difference of infection in the 1930 and $>50$ years age groups. The infection rates in male and female were $42.6 \%(\mathrm{Cl}: 29.2,56.8)$ and $37.3 \%$ (Cl: $28.9,46.4$ ) respectively. No significant association of $H$. pylori infection was observed with economic status, education level, occupation and tobacco consumption of the study population (Table-2).The rate of $H$. pylori infection in nondiabetic, pre-diabetic and diabetic individuals were $39.3 \%, 42.5 \%$ and $32.1 \%$ respectively. The rates were not significantly different from each other (Table-3).

\section{Discussion}

The present study, using ICT, found a low prevalence of $H$. pylori infection (38.9\%) in asymptomatic adult Bangladeshi rural population. Previously in 1997 and 2008, the seroprevalence rate of $>90 \%$ and $>70 \%$ were reported respectively in asymptomatic urban people from Bangladesh $[13,14]$. Similar decreasing trend was observed in South Korea [12]. Similar observation was made previously in Nepal where the infection rate in urban was $67.2 \%$ compared to $41.5 \%$ in rural population [19]. An Ethiopian study found a two- 
fold higher prevalence in an urban population than rural [20]. The explanation behind this difference might be increasing migration of people from rural to urban area causing higher urban density with crowded accommodation and poor living condition [21]. The low prevalence found in our study might be due to the improvement in socioeconomic standard of the local people and improved sanitation, hygiene or water supply in rural areas. Also, there could be some other unidentified factors that might inhibit $H$. pylori infection in our rural population. Though $H$. pylori has no known environmental reservoir, in Peru, the infection rate was lower in people using water from private wells than from municipal supply [22]. Also, exceptionally low $(7.0 \%)$ prevalence of $H$. pylori infection was reported among Malay peptic ulcer patients in north-eastern peninsular Malaysia [23]. Also, studies found that use of local strain to detect antibodies to $H$. pylori yielded a significantly improved sensitivity and specificity $[17,24,25]$.

In our study, the maximum infection rate was found in $\leq 30$ years of age group. People mostly acquire $H$. pylori during young age of life through feco-oral, oro-oral or gastro-oral transmission. The rate of infection becomes lower during later age due to lower exposure risk and decrease in susceptible individuals [3]. No significant difference between male and female was demonstrated in this study. Many previous studies reported similar finding $[26,27]$ whereas significantly higher prevalence of infection among men was also found in other studies $[28,29]$.

The study did not find any significant association of economic status, education and occupation with $H$. pylori infection suggesting that other risk factors likely exist which were not assessed in the current study. Additionally, the present study was conducted on a small number of relatively homogenous populations. We did not find any significant difference in $H$. pylori infection among non-diabetic, pre-diabetic and diabetic population having no symptom of gastritis or peptic ulcer disease. Also, in our previous study we did not find any significant difference in $H$. pylori infection in peptic ulcer patients with and without diabetes mellitus [30]. Thus, it appeared that diabetes was not a predisposing factor for $\mathrm{H}$. pylori infection.
In conclusion, our study has shown a low prevalence of $H$. pylori infection in adult rural population of Bangladesh. Further large scale studies covering additional possible risk factors and by using indigenous $H$. pylori strain derived antigen(s) are needed to determine the exact prevalence of $H$. pylori infection in urban and rural population of Bangladesh.

\section{References}

1. Suerbaum S, Michetti P. Helicobacter pylori infection. N Engl J Med. 2002; 347: 1175-1186.

2. Windle HJ, Kelleher D, Crabtree JE. Childhood Helicobacter pylori infection and growth impairment in developing countries: a vicious cycle? Pediatrics. 2007; 119(3): e754-759.

3. Miranda ACP, Machado RS, Koga da Silva EM, Kawakami E. Seroprevalence of Helicobacter pylori infection among children of low socioeconomic level in São Paulo. Sao Paulo Med J. 2010; 128(4): 187-191.

4. Kruszon-Moran D, McQuillan GM. Seroprevalence of six infectious diseases among adults in the United States by race/ethnicity: data from the third national health and nutrition examination survey, 1988--94. Adv Data. 2005; (352): 1-9.

5. Thjodleifsson $B$, Asbjörnsdottir $H$, Sigurjonsdottir RB, Gíslason D, Olafsson I, Cook E, et al. Seroprevalence of Helicobacter pylori and cagA antibodies in Iceland, Estonia and Sweden. Scand J Infect Dis. 2007; 39(8): 683-689.

6. O'Donohoe JM, Sullivan PB, Scott R, Rogers T, Brueton MJ, Barltrop D. Recurrent abdominal pain and Helicobacter pylori in a communitybased sample of London children. Acta Paediatr. 1996; 85(8): 961-964.

7. Yamashita Y, Fujisawa T, Kimura A, Kato H. Epidemiology of Helicobacter pylori infection in children: a serologic study of the Kyushu region in Japan. Pediatr Int. 2001; 43(1): 4-7.

8. Olmos JA, Ríos $H$, Higa R. Prevalence of Helicobacter pylori infection in Argentina: results of a nationwide epidemiologic study. 
Argentinean $\mathrm{Hp}$ epidemiologic study group. J Clin Gastroenterol. 2000; 31(1): 33-37.

9. Newton R, Ziegler JL, Casabonne D, Carpenter L, Gold BD, Owens M,et al. Helicobacter pylori and cancer among adults in Uganda. Infect Agent Cancer. 2006; 1: 5.

10. Malaty HM, Kim JG, Kim SD, Graham DY. Prevalence of Helicobacter pylori infection in Korean children: inverse relation to socioeconomic status despite a uniformly high prevalence in adults. Am J Epidemiol. 1996; 143(3): 257-262.

11. Aguemon BD, Struelens MJ, Massougbodji A, Ouendo EM. Prevalence and risk-factors for Helicobacter pylori infection in urban and rural Beninese populations. Clin Microbiol Infect. 2005; 11(8): 611-617.

12. Yim JY, Kim N, Choi SH, Kim YS, Cho KR, Kim $\mathrm{SS}$, et al. Seroprevalence of Helicobacter pylori in South Korea. Helicobacter. 2007; 12(4): 333-340.

13. Ahmad MM, Rahman M, Rumi AK, Islam S, Huq F, Chowdhury MF, et al. Prevalence of Helicobacter pylori in asymptomatic population--a pilot serological study in Bangladesh. J Epidemiol.1997; 7(4): 251-254.

14. Sumona AA, Hossain MA, Shamsuzzaman AKM, Musa AKM, Mahmud MC, Ali MS, et al. Anti-Helicobacter pylori IgG in asymptomatic population. Bangladesh J Med Microbiol. 2008; 2(02): 31-34.

15. Mahalanabis D, Rahman MM, Sarker SA, Bardhan PK, Hildebrand P, Beglinger C, et al. Helicobacter pylori infection in the young in Bangladesh: prevalence, socioeconomic and nutritional aspects. Int J Epidemiol. 1996; 25(4): 894-898.

16. Sarker SS, Rahman MM, Mahalanabis D, Bardhan PK, Hildebrand P, Beglinger $\mathrm{C}$, et al. Prevalence of Helicobacter pylori infection in infants and family contacts in a poor Bangladesh community. Dig Dis Sci. 1995; 40(12): 2669-2672.

17. Hoang TTH, Bengtsson C, Phung DC, Sörberg M, Granström M. Seroprevalence of Helicobacter pylori infection in urban and rural Vietnam. Clin Diagn Lab Immunol. 2005; 12(1): 81-85.

18. American Diabetes Association. Classification and diagnosis of diabetes mellitus. Diabetes Care. 2017; 34(1): 2-7.

19. Kawasaki, M, Kawasaki T, Ogaki T, Itoh K, Kobayashi S, Yoshimizu Y, et al. Seroprevalence of Helicobacter pylori infection in Nepal: low prevalence in an isolated rural village. Eur J Gastroenterol. 1998; 10: 47-49.

20. Lindkvist $\mathrm{P}$, Enquselassie F, Asrat D, Nilsson I, Muhe L, Giesecke J. Risk factors for infection with Helicobacter pylori: a study of children in rural Ethiopia. Scand J Infect Dis. 1998; 30: 371-376.

21. Aguemon BD, Struelens MJ, Massougbodji A, Ouendo EM. Prevalence and risk-factors for Helicobacter pylori infection in urban and rural Beninese populations. Clin Microbiol Infect. 2005; 11(8): 611-617.

22. Klein PD, Graham DY, Gaillour A, Opekun AR, Smith E. Water source as risk factor for Helicobacter pylori infection in Peruvian children. Lancet. 1991; 337: 1503-1506.

23. Raj SM, Yap K, Haq JA, Singh S, Hamid A. Further evidence of exceptionally low prevalence of Helicobacter pylori infection among peptic ulcer patients in north-eastern peninsular Malaysia. Trans $R$ Soc Trop Med Hyg. 2001; 95(1): 24-27.

24. Hoang $T T H$, Wheeldon TU, Bengtsson C, Phung DC, SörbergM, Granström M. Enzymelinked immunosorbent assay for Helicobacter pylori needs adjustment for the population investigated. J Clin Microbiol. 2004; 42: 627 630.

25. Romero-Gallo J, Perez-Perez GI, Novick RP, Kamath P, Norbu T, Blaser MJ. Responses of endoscopy patient in Ladakh, India, to Helicobacter pylori whole-cell and CagA antigens. Clin Diagn Lab Immunol. 2002; 9: 1313-1317.

26. Jimenez-Guerra F, Shetty $P$, Kurpad A Prevalence of and risk factors for Helicobacter pylori infection in school children in Mexico. Ann Epidemiol. 2000; 10: 474. 
27. Rothenbacher D, Bode G, Pesch F. Active infection with Helicobacter pylori in an asymptomatic population of middle aged to elderly people. Epidemiol Infect. 1998; 120: 297-303.

28. Liberato SVL, Galindo $\mathrm{MH}$, Alvarez $\mathrm{LT}$, Miramón FS, Ciriza SEL, Abadía AG,et al Helicobacter pylori infection in the child population in Spain: Prevalence, related factors and influence on growth. An Pediatr (Barc). 2005; 63(6): 489-494.
29. Murray L, McCrum EE, Evans AE. Epidemiology of Helicobacter pylori infection among 4742 randomly selected subjects from Northern Ireland. Int J Epidemiol. 1997; 26: 880-887.

30. Khatun S, Shadia K, Mahmud M, Mazumder S, Dutta IK, Rahman F, et al. Helicobacter pylori infection in diabetes mellitus patients with peptic ulcer disease. IMC J Med Sci. 2020; 14(2): 006 